\title{
Multiobjective Optimization Model of Residential Spatial Distribution
}

\author{
Xia Li, ${ }^{1}$ Chengxiang Zhuge, ${ }^{2}$ Xiang Zhang, ${ }^{1}$ Jian Gao, ${ }^{3}$ and Hui Zhang ${ }^{2}$ \\ ${ }^{1}$ School of Management and Economics, Beijing Institute of Technology, Beijing 100081, China \\ ${ }^{2}$ School of Traffic and Transportation, Beijing Jiaotong University, Beijing 100044, China \\ ${ }^{3}$ School of Science, Beijing Jiaotong University, Beijing 100044, China
}

Correspondence should be addressed to Chengxiang Zhuge; zgcx615@126.com

Received 27 April 2014; Revised 19 June 2014; Accepted 19 June 2014; Published 7 July 2014

Academic Editor: Robertt A. Valente

Copyright (C) 2014 Xia Li et al. This is an open access article distributed under the Creative Commons Attribution License, which permits unrestricted use, distribution, and reproduction in any medium, provided the original work is properly cited.

\begin{abstract}
The concept of jobs-housing balance has been adopted as an effective way to alleviate the traffic congestion, especially in metropolis. A multiobjective model of residential spatial distribution (MOOMRSD) is developed in this paper to address the problem of how to locate the housing in a reasonable way when the workplace location is given. Three objectives are integrated into the MOOMRSD and they are (1) minimizing the average commute cost from residence to workplace; (2) minimizing the total travel time of citizens; and (3) maximizing the aggregate utility and social benefit. In addition, a multiobjective genetic algorithm (MOGA) is proposed to figure out a satisfactory solution to the MOOMRSD. Finally, Both MOOMRSD and MOGA are applied into two cases.
\end{abstract}

\section{Introduction}

The residential spatial distribution has a close relationship with commute transport and whether the residences distribute reasonably has a significant effect on urban transport system. Urban planners have been working on alleviating the traffic congestion by balancing the jobs and housing and they consider jobs-housing balance as an effective policy. Jobs-housing balance policy is firstly proposed by Cervero in 1989 [1] and it is defined as equivalence in the number of jobs and the number of the residents seeking those jobs in a certain region. The goal of such policy attempts to address the problem of traffic jams by locating housing close to jobs. A few studies have focused on the issue of the jobs-housing balance. However, little paid attention to how to balance the jobs and housing, and, in other words, the method to locate the housing has not been widely studied. In order to overcome this limitation, this paper proposes a multiobjective optimization model of residential spatial distribution (MOOMRSD) for locating the housing. Besides, the multiobjective genetic algorithm (MOGA) is developed to figure out the solutions to MOOMRSD.

The rest of the paper is organized as follows. Section 2 reviews the literature about the jobs-housing balance and the factors affecting the residential location. Section 3 describes the MOOMRSD in detail. Section 4 proposes the MOGA which is particularly used for solving the multiobjective optimization problems. Section 5 carries out case study and both MOOMRSD and MOGA will be applied in two cases. Section 6 draws a conclusion. The last section is about conflict of interests.

\section{Literature Review}

This paper firstly reviews the literature about the jobshousing balance, and it can be found that study to date seldom paid attention to how to locate the housing according to the concept of jobs-housing balance. Then the paper continues to review the factors influencing the residential location.

2.1. Study on Jobs-Housing Balance. A few studies have focused on the issue of the jobs-housing balance. Wachs et al. [2] investigated the jobs-housing relationship over time. Horner and Murray [3] proposed a multiobjective approach to improve the regional jobs-housing balance. John Miller [4], Zhao et al. [5], and Sultana [6] analyzed the impact of jobs-housing balance on urban commuting and 
they took Virginia, Beijing, and Atlanta metropolitan area as example, respectively. Besides, Wang and Chai [7] employed the structural equations model to investigate the interactions between housing source, jobs-housing relationship, transport mode, and commuting time in Beijing. Loo and Chow [8] introduced a geographical approach to study the jobshousing balance and minimum commute under different population structures. Giuliano [9] conducted a research on whether jobs-housing balance was an effective solution for traffic congestion and air pollution concerns; similarly, Lobyaem [10] studied the effectiveness of jobs-housing balance as a strategy for reducing traffic congestion. Peng [11] applied GIS and a piece-wise, nonlinear model to empirically analyze the relationship between the jobs-housing ratio and urban commuting patterns. Wu [12] provided theoretical and empirical evidence of jobs-housing balance and examined the applicability of jobs-housing balance ratio for different planning purpose in local context. Ma and Banister [13] and Layman and Horner [14] proposed methods to evaluate the balance of jobs-housing.

\subsection{Study on Factors Influencing the Residential Location.} The residential location is influenced by a few factors [2]. Workplace location and accessibility are commonly approved to be two central factors. Waddell [15] examined the interactions within single and dual-worker households between workplace location, residential mobility, housing tenure, and location choice. Inoa et al. [16] employed a three-level Nested Logit model to investigate the relationship among the residential location, workplace, and job type. Waddell [17] developed a Nested Logit model of workers' choices of workplace, residence, and housing tenure to examine the assumption that the choice of workplace is exogenously determined. Rivera and Tiglao [18] developed a disaggregated residential location choice, workplace location choice, and mode choice for two-worker households in Metro Manila. Pinjari et al. [19] proposed an integrated model of residential location, autoownership, bicycle ownership, and commute tour mode choice decisions. Ibeas et al. [20] used the Nested Logit and Cross-Nested Logit models of residential location choice to investigate the existence of spatial correlation between different locations, such as workplace location. Cho et al. [21] took Mecklenburg County, North Carolina, as example and adopted both Conditional Logit models and Heteroscedastic Logit models to explore the role of employment subcenters in determining residential location decisions.

2.3. Limitations of Study to Date. Based on the above literature review, two limitations can be concluded as follows.

First, based on the review about jobs-housing balance (Section 2.1), it is clear that previous studies concerning jobs-housing balance mainly focused on the impact of jobshousing balance, evaluation of jobs-housing balance, and so forth; seldom did researchers pay attention to how to balance the jobs and housing, and, in other words, the method to locate the housing has not been widely studied.
Second, on the basis of literature review regarding the influence factors of residential location, especially the workplace location and accessibility, it can be safely concluded that most of previous studies focused on the relationship between residential location and other elements, such as workplace location and accessibility; however, the influence factors pointed out have not been applied to analyze the residential location.

This paper tries to overcome the limitations above and its contributions are as follows.

To the first limitation, a multiobjective optimization model of residential spatial distribution (MOOMRSD) is proposed and it is used for reasonably locating the housing and achieving the jobs-housing balance. Besides, the multiobjective genetic algorithm (MOGA) is developed to figure out the solutions to MOOMRSD.

To the second limitation, both workplace location and accessibility, in this paper, will be adopted as chief factors and used to locate the housing. That is, both of them will be taken into consideration when modeling the MOOMRSD.

\section{Multiobjective Optimization Model of Residential Spatial Distribution (MOOMRSD)}

Jobs-housing balance aims at locating the housing reasonably. In most cases, the residential areas have been given, which is determined in the urban planning. So the reaming question is how many houses should be allocated to each residential area. Under a few of constraints, MOOMRSD is used to figure out the reasonable number of houses in each residential area with several objectives. More details about the modeling process will be given in the following sections.

3.1. Basic Assumption. It is assumed that a road network can be simplified to weighed direct graph $G=(N, A, L) . N$, $A$, and $L$ denote the points set, arcs set, and weight matrix, respectively. The points set $N$ consists of residential and workplace nodes; if the number of the points in the set is $n$, then $N=\{1,2, \ldots, n\}$; the $\operatorname{arcs}$ set $A$ contains arcs linking residential nodes to workplace nodes or residential nodes to residential nodes. An arc can be denoted as $a_{i j}=\left(i, j, l_{i j}\right)$, $a_{i j} \in A, l_{i j} \in L, i, j \in N . l_{i j}$ represents the weight (length) of $\operatorname{arc} a_{i j}$. Besides, the flows between nodes make up the $O-D$ (Origin-Destination) matrix $Q=\left(q_{i j}\right) \cdot q_{i j}$ denotes the flow from node $i$ and node $j . O_{i}$ denotes the total generated flow volume of residential nodes and $D_{i}$ denotes the total attracted flow volume of workplace nodes. The relationship among $q_{i j}$, $O_{i}$, and $D_{i}$ is presented as follows:

$$
O_{i}=\sum_{j \in N} q_{i j}, \quad D_{j}=\sum_{i \in N} q_{i j} .
$$

3.2. Objective Functions. MOOMRSD sets up three objectives and they are as follows. (1) Objective 1 aims at minimizing the average commute cost from residence to workplace. (2) Objective 2 aims at minimizing the total travel time of citizens. (3) Objective 3 aims at maximizing the aggregate 
utility and social benefit. Objective 1 reflects the individual demand, while both Objective 2 and Objective 3 reflect the overall interests of whole cities. However, Objective 2 and Objective 3 emphasize the time and money, respectively.

More details about the above three objectives are as follows.

Objective 1. Minimizing the Average Commute Cost from Residence to Workplace. The function of Objective 1 is presented as follows:

$$
\begin{array}{ll}
\text { Min } & Z_{1}=\frac{1}{N} \sum_{r=1}^{m} \sum_{s=1}^{n} S_{r s} q_{r s} \\
\text { s.t. } \quad & \sum_{r=1}^{n} q_{r s}=W_{s} \quad \forall j=1, \ldots, m \\
& \sum_{s=1}^{m} q_{r s}=H_{r} \quad \forall i=1, \ldots, n \\
& q_{r s} \geq 0 \quad \forall i, j,
\end{array}
$$

where $m$ denotes the number of residential nodes; $n$ denotes the number of workplace nodes; $H_{r}$ denotes the generated flow volume in node $r ; W_{s}$ denotes the attracted flow volume in node $s ; q_{r s}$ denotes the total travel volume from node $r$ to node $s ; N$ denotes the total flow volume; $S_{r s}$ denotes the travel cost from node $r$ to node $s$. $S_{r s}$ includes time cost and monetary cost and it can be calculated as follows:

$$
S_{r s}=\varphi\left(t_{r s}\right)+\delta\left(C_{r s}\right)
$$

where $\varphi\left(t_{r s}\right)$ is the function of time cost and $\delta\left(C_{r s}\right)$ is the function of monetary cost.

Assuming that the number of houses in node $r$ is equal to the number of flow volume $H_{r}$, similarly, the attracted flow volume of node $s\left(W_{s}\right)$ is equal to the number of employees in node $s$.

Objective 2. Minimizing the Total Travel Time of Citizens. The function of Objective 2 is presented as follows:

$$
\operatorname{Min} Z_{2}(t, q)=\sum_{r} \sum_{s} t_{r s} \cdot q_{r s}
$$

where $t_{r s}$ denotes the total travel time from node $r$ to node $s$, and it is made up of the travel time of each link $t_{a}$. $t_{r s}$ can be calculate as follows:

$$
t_{r s}=\sum_{a} t_{a} \cdot \delta_{a k}^{r s}
$$

where if link $a$ is one part of route $k$ which links residential node $r$ to workplace node $s$, then $\delta_{a k}^{r s}=1$; otherwise, $\delta_{a k}^{r s}=0$.

Objective 3. Maximizing the Aggregate Utility and Social Benefit. Under the constraint of personal income, the citizens make the tradeoff between housing cost and commute cost (including time cost and monetary cost). It is assumed that there is a linear relationship between commuters' utility and income. Besides, commuters who work in the same work place have the same utility. The utility function for commuters, who live in residential node $r$ and work in workplace node $s$, can be calculated as follows:

$$
U_{r s}=w(s)-p_{r}-S_{r s}+\varepsilon_{r s},
$$

where $w(s)$ denotes the income of commuters in workplace node $s ; p_{r}$ denotes the price of residential node $r ; \varepsilon_{r s}$ denotes the random variable obeying Gumbel distribution.

Then the function of Objective 3 can be presented as follows:

$$
\operatorname{Max} Z_{3}=\sum_{r} \sum_{s} U_{r s}
$$

Objective 3 is under two constraints and they are as follows.

Constraint 1. From the view of sustainability, the concept of Jobs-housing balance should be placed emphasis on, so that the land resources can be wisely used. Jobs-housing balance means that the commute time/distance is reasonable and supply of houses and jobs meets the demand of citizens well. In order to keep the jobs-housing balance, there is a relationship among $W_{s}, H_{r}$, and $H$, and the relationship can be presented as follows:

$$
\sum_{s} W_{s}=\sum_{r} H_{r}=H
$$

Constraint 2. The sum of land rent and commute cost should be less than income, which is presented as follows:

$$
w(s)-p(r)-C_{r s}>0,
$$

where $w(s)$ denotes the income; $p(r)$ denotes the land rent.

The above three objectives and their constraints are summarized as follows:

$$
\begin{array}{ll}
\text { Min } & Z_{1}=\frac{1}{N} \sum_{r=1}^{m} \sum_{s=1}^{n} C_{r s} q_{r s} \\
\text { Min } \quad & Z_{2}=\sum_{r} \sum_{s} t_{r s} \cdot q_{r s} \\
\text { Max } \quad & Z_{3}=\sum_{r} \sum_{s} U_{r s} \\
& \\
\text { s.t. } \quad \sum_{r=1}^{n} q_{r s}=W_{s}, \quad \forall j=1, \ldots, m \\
& w(s)-p(r)-C_{r s}>0 \\
& q_{r s} \geq 0, \quad \forall i, j \\
& \sum_{s} W_{s}=\sum_{r} H_{r}=H \\
& \sum_{s=1}^{m} q_{r s}=H_{r}, \quad \forall i=1, \ldots, n .
\end{array}
$$


3.3. Traffic Assignment Model. In the MOOMRSD, traffic flow and travel time are two basic variables which has a significant influence on the objective values. Both of them are calculated in the traffic assignment model. The traffic assignment model, in this paper, firstly finds out the shortest path for each OD (origin-destination) pair and then loads the traffic flow to the road network. The classical shortest path algorithm Dijkstra is employed and the travel time is used as the weight (cost) in the Dijkstra algorithm.

Travel time has a relationship with the traffic flow and it can be calculated by BPR function represented as follows:

$$
t_{i}\left(q_{i}\right)=t_{i}(0)\left[1+\alpha\left(\frac{q_{i}}{C_{i}}\right)^{\beta}\right], \quad i=1,2, \ldots, a,
$$

where $t_{i}\left(q_{i}\right)$ denotes the travel time on link $i ; t_{i}(0)$ denotes the travel time when the link $i$ stays at the free flow status; $C_{i}$ denotes the capacity of link $i$, namely, the maximum number of vehicles passing the link $i . \alpha$ and $\beta$ are retardation factors.

\section{Multiobjective Genetic Algorithm (MOGA)}

MOGA consists of two steps: the first step is to determine the weight of each objective and the next step is to address the problem by using genetic algorithm.

4.1. Objective Weight. There are multiobjectives involving the optimization problem. To what extend does each objective affect the optimization result should be firstly addressed. Usually, the weight of each objective is employed to express the contribution of each objective. The higher the weight is, the more the objective contributes. The weight is also used to turn the multiobjective problem into single-objective problem. The transformation process can be presented by (12). The objective values may vary in units and order of magnitudes; because of this, the initial objective values should be standardized before they are integrated into a single objective value:

$$
\operatorname{Min}(\operatorname{Max}) w_{1} \cdot \mathrm{Obj}_{1}+\cdots+w_{i} \cdot \mathrm{Obj}_{i}+\cdots+w_{n} \cdot \mathrm{Obj}_{n},
$$

where $\mathrm{Obj}_{i}$ denotes the standardize value of $i$ th objective; $w_{i}$ denotes the weight of $i$ th objective.

Then how to determine the weight of the objective is the next question to be discussed. There are a few methods to determine the weight, like Analytic Hierarchy Process (AHP) [22, 23], Coefficient of Variation Method [24], Grey Correlation Method [25], Entropy Method [26], and so forth. The AHP is adopted in this paper and the reasons are as follows.

Firstly, the AHP is a typical method to calculate the weights and its perfect performance has been proved. Therefore, we can safely apply the method to the optimization problem here.

Second, several stakeholders, such as governors, individuals, and property developers, get involved in the optimization of residential optimization. A qualified weight calculation method should take the benefits of all stakeholders into account. In AHP, the weights are calculated based on the score of each stakeholder, which makes the weight reflect stakeholders' expectation roundly.

4.2. Rank-Based Genetic Algorithm (RB-GA). An improved genetic algorithm called Rank-Based Genetic Algorithm (RB-GA) is employed here to search for the solution to MOOMRSD. The difference between RB-GA and traditional GA is in the fitness function. More details will be given during the introduction to RB-GA. Being similar to traditional GA, the RB-GA is also mainly made up of encoding, population initialization, fitness function, selection, crossover, mutation, and stop criterion. Selection, mutation, and crossover are three kinds of genetic manipulation. The process of RB-GA will be described step by step.

Step 1 (encoding). By encoding, the solution to the problem is translated and placed onto the chromosome. Three typical encoding methods are available and they are binary coding, gray coding, and real-number encoding. Real-number encoding is adopted in the case study of this paper.

Step 2 (population initialization). In this step, a certain number of chromosomes will be randomly generated and the population size will be predefined. Such initial population can be seen as the initial population based on which the population evolves.

Step 3 (fitness function). Fitness value is used to evaluate every chromosome in the population. During the evolution, the chromosome with high fitness value is more likely to be kept than the one with low fitness value. The fitness function in RB-GA differs from the one in the traditional GA. Traditionally, the objective value will be used as the fitness value. However, the objective values, in multiobjective problem, may vary in units and order of magnitudes; because of this, the initial objective values should be standardized before they are integrated into a single objective value. The standardization method in RB-GA is implemented by ranking the objective values. That is to say, three objective values of different chromosome will be separately ranked first, and then the fitness value is the weighted sum of the ranking of these three objective values. Equation (13) is used for calculating such fitness $S_{i}$ :

$$
S_{i}=\sum_{j=1}^{3} g_{i}^{j},
$$

where $S_{i}$ denotes the fitness value of $i$ th chromosome; $g_{i}^{j}$ denotes the ranking of the $j$ Objective of $i$ th chromosome.

Step 4 (selection). This step will select chromosomes from population based on the fitness value. The chromosome with high fitness value is more likely to be kept than the one with low fitness value, and this phenomenon can be described as follows:

$$
w_{k}=\frac{S_{k}}{\sum_{j=1}^{K} S_{j}}, \quad k=1,2, \ldots, K
$$


where $w_{k}$ denotes the probability of $k$ th chromosome to be selected; $S_{k}$ and $S_{j}$ denote the fitness value of $k$ th and $j$ th chromosome, respectively. $K$ is the number of the population size.

Step 5 (crossover). Crossover, which is one type of evolution, makes two chromosomes exchange their allelic genes. In this way, two new chromosomes come into being. Crossover probability $p_{c}$ is proposed here to determine how many chromosomes participate in such evolution.

Step 6 (mutation). Mutation, another type of evolution, makes one or more genes in the chromosomes change to another genes carrying different information. Similarly, the mutation probability $p_{m}$ is employed to ensure the number of chromosomes taking part in the mutation.

Step 7 (stop criterion). Usually, two stop criterions are used in the GA. One is about the maximum iteration, the other is about the fitness value. Both of them can be predefined.

\section{Case Study}

The application of the MOOMRSD proposed in this paper has significant social benefits. As discussed above, the MOOMRSD is mainly used for locating the housing based on the concept of jobs-housing balance. When the MOOMRSD is applied into the urban planning, the residential spatial distribution will be much more reasonable and citizens can really benefit from it a lot. For example, citizens, who live in a city that has a balance between jobs and housing, can dramatically reduce their travel time and cost.

In order to examine the applicability of both MOOMRSD and MOGA, two case studies will be carried out. In Case 1, the total number of jobs is fixed, but the capacity of each workplace node is unlimited. In Case 2, both the total number of jobs and the capacity of each workplace node are fixed. A simplified road network showed by Figure 1 is used for case study. The network is made up of 12 residential nodes, 4 workplace nodes, and direct arcs between two nodes. Besides, the total number of jobs is set to 2000 and these jobs are in 4 workplace nodes. The length of straight line and oblique line are set to 100 and 141, respectively.

5.1. Case 1. In Case 1, the total number of jobs is fixed, but the capacity of each workplace node is unlimited. The problem to be addressed is to figure out both the number of houses in each residential node and the number of jobs in each workplace node, which can be illustrated by Figure 2 transformed from Figure 1. It can be seen from Figure 2 that 2000 jobs will be firstly allocated to 4 workplace nodes and then the jobs in each work node will be assigned to 12 residential nodes. Thus, the sum of jobs in 12 residential nodes is equal to 2000. It is assumed that the number of jobs in each residential node is equal to the number of houses; therefore, when the number of jobs in each residential node is figured out, the number of houses will subsequently be determined.
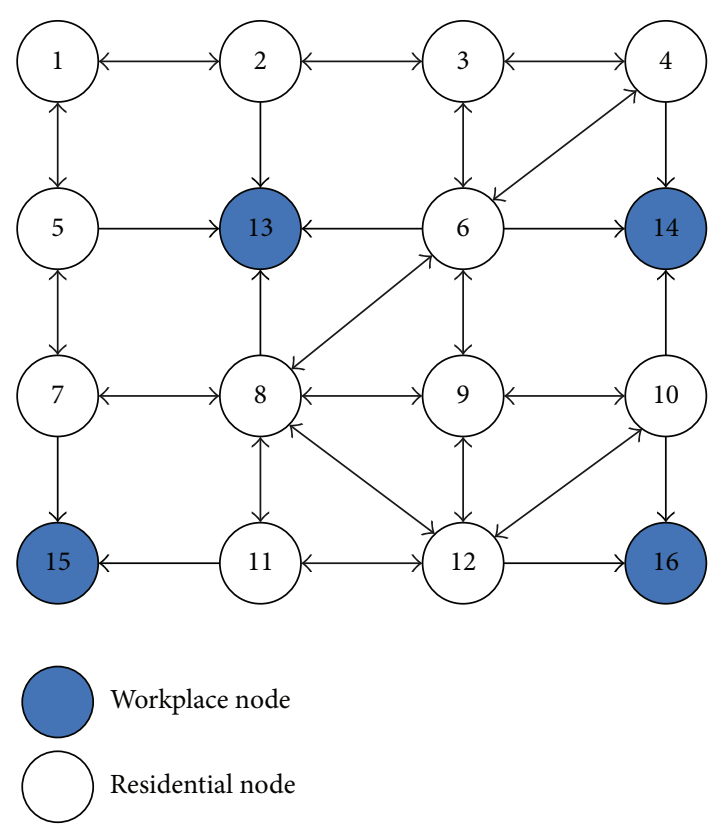

Figure 1: Simplified road network.

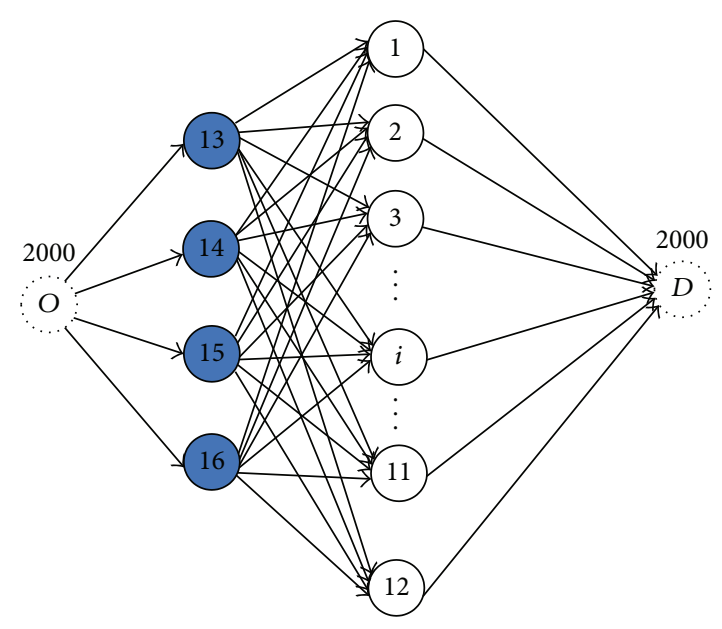

FIgURE 2: Transformed road network in Case 1.

TABLE 1: A table filled out by a professional researcher.

\begin{tabular}{lccc}
\hline & Objective 1 & Objective 2 & Objective 3 \\
\hline Objective 1 & 1 & 2 & 4 \\
Objective 2 & 0.5 & 1 & 2 \\
Objective 3 & 0.25 & 0.5 & 1 \\
\hline
\end{tabular}

5.1.1. Preparation. By using MOOMRSD and RB-GA, the problem stated in Case 1 can be finally solved. The objective weight, encoding approach, and the primary parameters in RB-GA are specifically pointed out as follows.

(1) Objective Weight. The AHP method is adopted to calculate the objective weight. Ten professional researchers are invited to give the weight of these objectives. They have to fill a table showed by Table 1 . Take Table 1, for example; the research 


\begin{tabular}{|c|c|c|c|c|c|c|c|c|c|c|c|c|c|c|}
\hline \multicolumn{15}{|c|}{$\leftarrow$ Workplace zones $\rightarrow \leftarrow \begin{array}{c}\text { Workplace } \\
\text { zone 1 }\end{array} \rightarrow \begin{array}{c}\text { Workplace } \\
\text { zone 2 }\end{array} \rightarrow \leftarrow \begin{array}{c}\text { Workplace } \\
\text { zone 3 }\end{array} \rightarrow \begin{array}{c}\text { Workplace } \\
\text { zone 4 }\end{array} \rightarrow$} \\
\hline 0.1 & 0.3 & 0.2 & 0.4 & 0.1 & $\ldots$ & 0.2 & 0.1 & 0.2 & 0.1 & $\ldots$ & 0.2 & 0.1 & $\ldots$ & 0.2 \\
\hline
\end{tabular}

FIgURE 3: Encoding approach in Case 1.

considers that the Objective 1 is two times as important as the Objective 2, so he fills 2 in the corresponding blank. On the basis of the 10 tables scored by the 10 professional researchers, the final objective weights can be calculated by averaging the weight given by these ten researchers. The weights of Objective 1, Objective 2, and Objective 3 are $0.2,0.5$, and 0.3 , respectively.

(2) Encoding Approach. Real-number encoding approach is adopted here and the encoding approach in Case 1 is showed by Figure 3. There are 52 genes on each chromosome. As for the first four genes, they carry the information about the weight of 4 workplace nodes. For example, the weight of first workplace node is 0.1 , so the number of jobs allocated to it is $200(=2000 \times 0.1)$. The subsequent 12 genes carry the information about the weights of 12 residential nodes linking to the first workplace node. For instance, the weight of first residential node is 0.1 , so the number of jobs allocated to it is $20(=2000 \times 0.1 \times 0.1)$. Similarly, the weights information related to rest of workplace nodes is stored in the subsequent genes.

\section{(3) Primary Parameters in $R B-G A$}

(i) Population size: 200.

(ii) Maximum iterations: 200.

(iii) Minimum change of rate: 0.05 .

(iv) Mutation probability: 0.01 .

(v) Crossover probability: 0.01.

5.1.2. Performance Assessment. The performance of the MOOMRSD and RB-GA in Case 1 is as follows.

(1) The Performance of MOOMRSD. Those three objectives (average commute cost, total travel time of citizens, and social benefit) are chosen as the parameters to assess the performance of MOOMRSD, since they can reflect the MOOMRSD's ability to find out a solution meeting the requirement of jobs-housing balance.

A comparison between the solution found out by using MOOMRSD and 100 solutions generated randomly is carried out. Being similar to the fitness value calculated by the MOGA, the values of three parameters will be firstly ranked, and then they will be integrated into the aggregate value, which is calculated by (12). If a solution has a high aggregate value, it can be concluded that the solution is balancing the jobs and housing well. Figure 4 demonstrates the comparison result. It can be seen from Figure 4 that the aggregate value of the solution found out by using MOOMRSD is much higher than the ones generated randomly. Therefore, it is clear that the performance of MOOMRSD is good and MOOMRSD

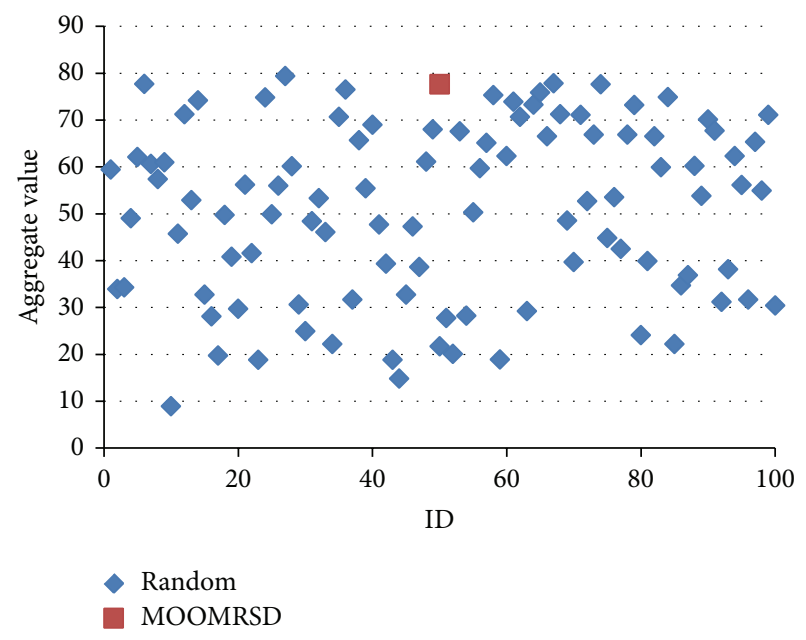

FIGURE 4: Comparison between solutions calculated by MOOMRSD and generated randomly in Case 1.

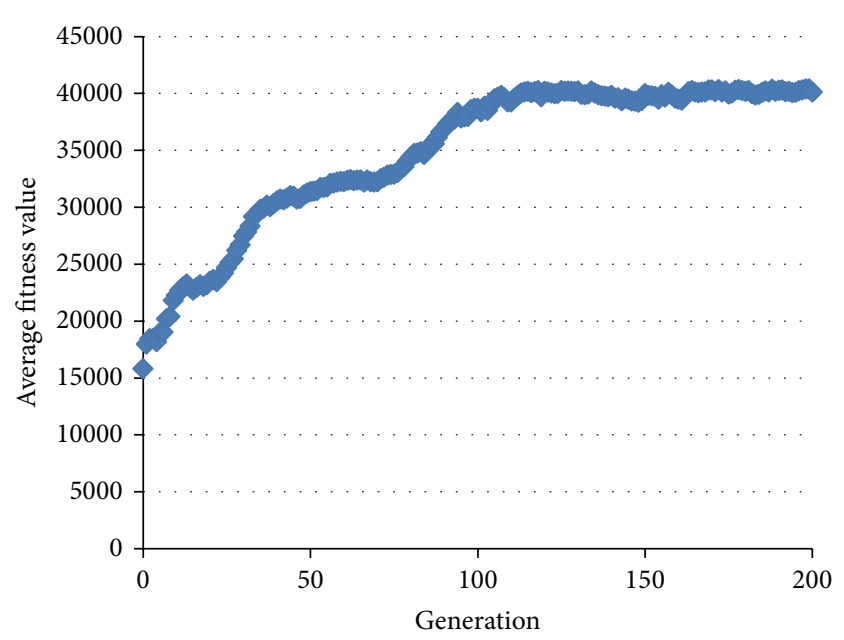

Figure 5: The average fitness value of each generation in Case 1.

was able to figure out a solution meeting the requirement of jobs-housing balance.

(2) The Performance of RB-GA. The performance of RB-GA is evaluated by the average fitness value of each generation. In Case 1, the average fitness value of each generation is demonstrated by Figure 5. It can be seen from Figure 5 that the average fitness value grows significantly from generation 0 to 120 , and then it keeps stable. That is to say, the best solution is found out in the generation 120. Therefore, it can be concluded that RB-GA has the ability to gradually find out 
TABLE 2: The number of jobs in each workplace node.

\begin{tabular}{lcccc}
\hline Workplace node ID & WZ1 & WZ2 & WZ3 & WZ4 \\
\hline The number of jobs & 384 & 336 & 869 & 409 \\
\hline
\end{tabular}

the best solution, and it performs well when it is applied to solve the model of MOOMRSD.

5.1.3. Results. By using the RB-GA, the number of jobs in each workplace node and houses in each residential node can be simultaneously calculated. The detailed results are as follows.

(1) The Number of Jobs in Each Workplace Node. The number of jobs of workplace in workplace nodes $13,14,15$, and 16 are $384,336,869$, and 409 , respectively, which is showed by Table 2 .

(2) The Number of Houses in Each Residential Node. The number of houses in residential nodes 1 to 12 are 152, 157, 180, $128,177,171,167,172,178,184,160$, and 171, respectively, which is showed by Table 3 .

(3) The Objective Values. The values of Objective 1, Objective 2 , and Objective 3 are $2.97 \times 10^{10}, 20307854$, and 60364 , respectively.

5.2. Case 2. In Case 2, both the total number of jobs and capacity of each workplace node are fixed. The problem to be addressed is to figure out both the number of houses in each residential node, which can be illustrated by Figure 6 transformed from Figure 1. It can be seen from Figure 6 that 2000 jobs have been already allocated to 4 workplace nodes and the number of jobs of workplace nodes $13,14,15$, and 16 are $300,600,400$, and 700 , respectively. The jobs in each work node will be assigned to 12 residential nodes in a proper way, so that the number of houses in each residential node can be known.

5.2.1. Preparation. Being similar to Case 1 , both MOOMRSD and RB-GA are applied into Case 2 and the number of houses in each residential node can be figured out. The objective weight and the primary parameters in RB-GA are the same to those in Case 1. Only the way how to encode will be discussed. The encoding approach in Case 2 is similar to that in Case 1. The difference between these two cases is in the weight of workplace nodes. Briefly, there are four genes carrying the information about the weight of workplace nodes in the front of the chromosome in Case 1; however, there are no such genes in Case 2. Figure 7 shows the encoding approach in Case 2.

5.2.2. Performance Assessment. The performance assessment in Case 2 is similar to the one in Case 1; the performance of the MOOMRSD and RB-GA in Case 2 is as follows.

(1) The Performance of MOOMRSD. Figure 8 shows the comparison between solutions calculated by MOOMRSD

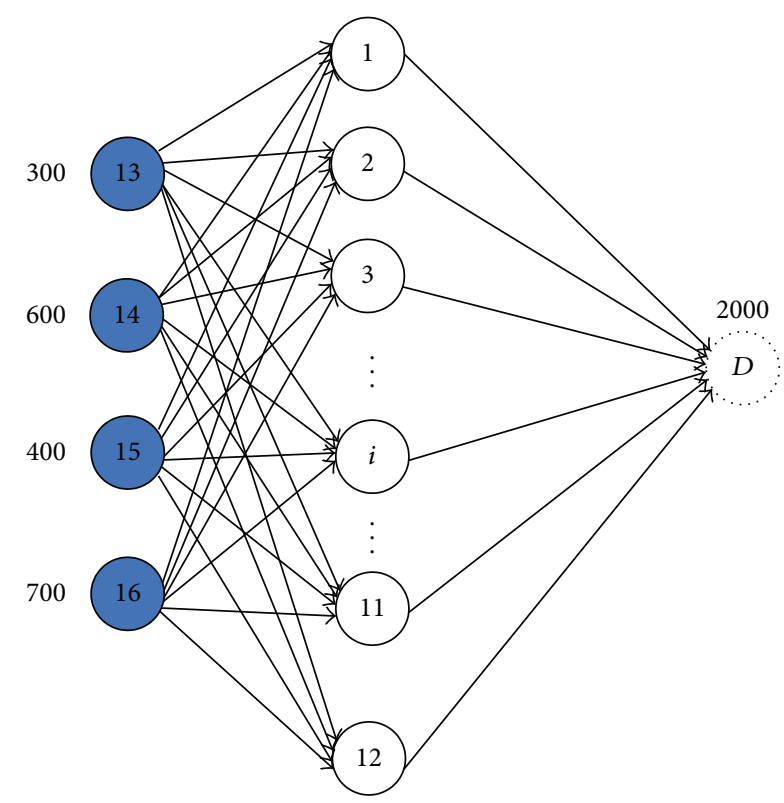

FIgURE 6: Transformed road network in Case 2.

\begin{tabular}{|c|c|c|c|c|c|c|c|c|c|c|c|}
\hline \multicolumn{3}{|c|}{$\leftarrow \begin{array}{c}\text { Workplace } \\
\text { zone } 1\end{array}$} & \multicolumn{3}{|c|}{$\begin{array}{c}\text { Workplace } \\
\text { zone } 2\end{array}$} & \multicolumn{3}{|c|}{$\begin{array}{c}\text { Workplace } \\
\text { zone } 3\end{array}$} & \multicolumn{3}{|c|}{$\begin{array}{c}\text { Workplace } \\
\text { zone } 4\end{array} \rightarrow$} \\
\hline 0.1 & $\ldots$ & 0.2 & 0.1 & $\ldots$ & 0.2 & 0.1 & $\ldots$ & 0.2 & 0.1 & $\ldots$ & 0.2 \\
\hline
\end{tabular}

Figure 7: Encoding approach in Case 2.

and generated randomly in Case 2. It can be seen from Figure 8 that the aggregate value of the solution found out by using MOOMRSD is much higher than the ones generated randomly. Therefore, it also can be concluded that the performance of MOOMRSD in Case 2 is good.

(2) The Performance of RB-GA. Figure 9 demonstrates the average fitness value of each generation in Case 2. On the basis of Figure 9, it is clear that the average fitness value goes up dramatically form generation 0 to 50 , and then it keeps stable. That is to say, the best solution is found out in the generation 50. Therefore, it can be concluded that RB-GA has the ability to find out the best solution gradually.

5.2.3. Results. By using the RB-GA, the number of houses in each residential node can be calculated. The detailed results are as follows.

(1) The Number of Houses in Each Residential Node. The number of houses in residential nodes 1 to 12 are 152, 157, 180, $128,177,171,167,172,178,184,160$, and 171 , respectively, which is showed by Table 4 .

(2) The Objective Values. The values of Objective 1, Objective 2 , and Objective 3 are $2.99 \times 10^{10}, 20305991$, and 60000, respectively. 
TABLE 3: The number of houses in each residential node.

\begin{tabular}{|c|c|c|c|c|c|c|c|c|c|c|c|c|}
\hline $\begin{array}{l}\text { Residential } \\
\text { node ID }\end{array}$ & $\mathrm{RZ1}$ & RZ2 & RZ3 & RZ4 & RZ5 & RZ6 & RZ7 & RZ8 & RZ9 & RZ10 & RZ11 & RZ12 \\
\hline $\begin{array}{l}\text { The number } \\
\text { of houses }\end{array}$ & 161 & 156 & 145 & 208 & 161 & 201 & 144 & 156 & 159 & 159 & 197 & 151 \\
\hline
\end{tabular}

TABLE 4: The number of houses in each residential node.

\begin{tabular}{|c|c|c|c|c|c|c|c|c|c|c|c|c|}
\hline $\begin{array}{l}\text { Residential } \\
\text { node ID }\end{array}$ & $\mathrm{RZ1}$ & RZ2 & RZ3 & $\mathrm{RZ4}$ & RZ5 & RZ6 & RZ7 & RZ8 & RZ9 & RZ10 & RZ11 & RZ12 \\
\hline $\begin{array}{l}\text { The number } \\
\text { of houses }\end{array}$ & 152 & 157 & 180 & 128 & 177 & 171 & 167 & 172 & 178 & 184 & 160 & 171 \\
\hline
\end{tabular}

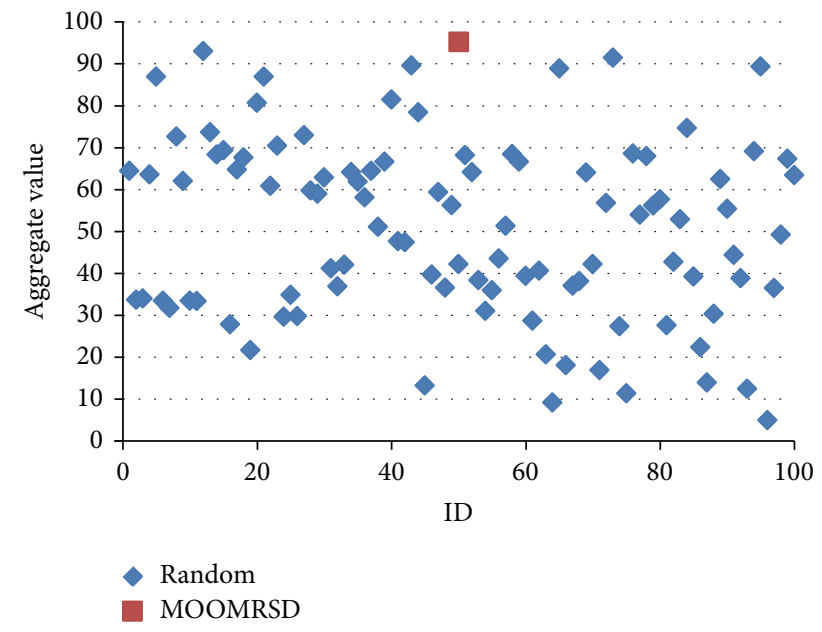

FIGURE 8: Comparison between solutions calculated by MOOMRSD and generated randomly in Case 2 .

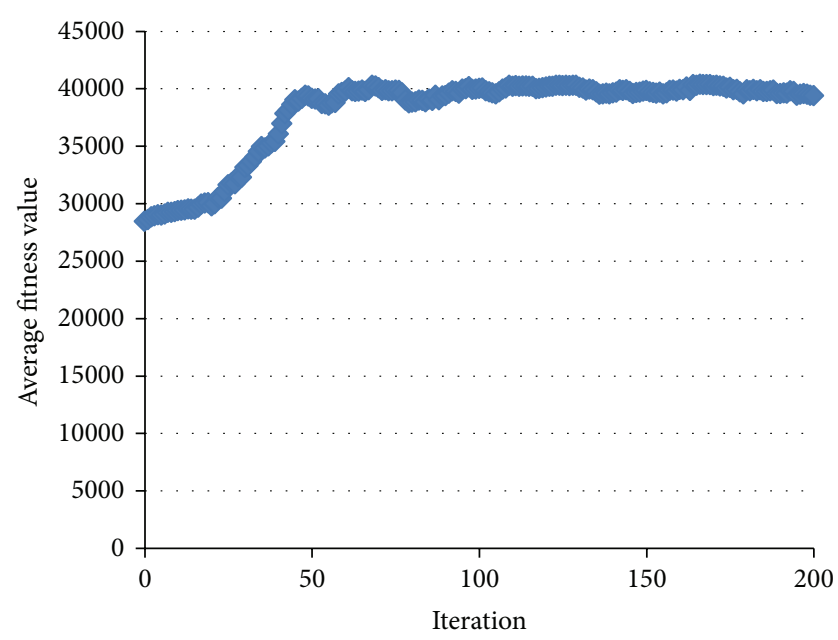

FIGURE 9: The average fitness value of each generation in Case 2.

\section{Conclusion}

The concept of jobs-housing balance is adopted to optimize the residential distribution. As previous study seldom focused on balancing the jobs and housing, as well as applying the factors of workplace location and accessibility to locate the housing, a multiobjective model of residential spatial distribution (MOOMRSD) is developed in this paper. MOOMRSD takes different stakeholders into account and aims at optimizing the residential distribution under a few objectives and constrains. Minimizing the average commute cost from residence to workplace, minimizing the total travel time of citizens, and maximizing the aggregate utility and social benefit are there objectives in MOOMRSD. In order to solve the model effectively and efficiently, the multiobjective genetic algorithm (MOGA) is developed for figuring out the solution to the MOOMRSD. In the MOGA, Analytic Hierarchy Process is firstly applied to determine the weights of three objectives and then the multiobjective optimization problem can be changed into single-objective optimization problem, which makes the solution procedure much simpler. Besides, in order to overcome the shortcoming of traditional genetic algorithm, the Rank-Based Genetic Algorithm is proposed to tackle the problem of different units and order of magnitudes of objective values. Finally, both MOOMRSD and MOGA are successfully applied to two cases. Therefore, it can be seen that MOOMRSD is a qualified model for resident spatial optimization and MOGA is an effective algorithm to search for the solution to MOOMRSD.

\section{Conflict of Interests}

The authors declare that there is no conflict of interests regarding the publication of this paper.

\section{References}

[1] R. Cervero, "Jobs-housing balancing and regional mobility", Journal of the American Planning Association, vol. 55, no. 2, pp. 136-150, 1989.

[2] M. Wachs, B. D. Taylor, N. Levine, and P. Ong, "The changing commute: a case-study of the jobs-housing relationship over time," Urban Studies, vol. 30, no. 10, pp. 1711-1729, 1993.

[3] M. W. Horner and A. T. Murray, "A multi-objective approach to improving regional jobs-housing balance," Regional Studies, vol. 37, no. 2, pp. 135-146, 2003.

[4] J. Miller, "Impact of jobs-housing balance on average jurisdiction commuting times: virginia macroscopic analysis," Transportation Research Record, no. 2244, pp. 18-26, 2011. 
[5] P. Zhao, B. Lü, and G. D. Roo, "Impact of the jobs-housing balance on urban commuting in Beijing in the transformation era," Journal of Transport Geography, vol. 19, no. 1, pp. 59-69, 2011.

[6] S. Sultana, "Job/housing imbalance and commuting time in the atlanta metropolitan area: exploration of causes of longer commuting time," Urban Geography, vol. 23, no. 8, pp. 728-749, 2002.

[7] D. Wang and Y. Chai, "The jobs-housing relationship and commuting in Beijing, China: the legacy of Danwei," Journal of Transport Geography, vol. 17, no. 1, pp. 30-38, 2009.

[8] B. P. Y. Loo and A. S. Y. Chow, "Jobs-housing balance in an era of population decentralization: an analytical framework and a case study," Journal of Transport Geography, vol. 19, no. 4, pp. 552-562, 2011.

[9] G. Giuliano, "Is jobs-housing balance a transportation issue?" Transportation Research Record, no. 1305, pp. 305-312, 1991.

[10] S. Lobyaem, The Effectiveness of Jobs-Housing Balance as a Strategy for Reducing Traffic Congestion: A Study of Metropolitan Bangkok, Texas A\&M University, 2006.

[11] Z. R. Peng, "The jobs-housing balance and urban commuting," Urban Studies, vol. 34, no. 8, pp. 1215-1235, 1997.

[12] Q. Wu, Jobs-Housing Balance: The Right Ratio for the Right Place, The University of Texas at Austin, 2013.

[13] K. R. Ma and D. Banister, "Extended excess commuting: a measure of the jobs-housing imbalance in Seoul," Urban Studies, vol. 43, no. 11, pp. 2099-2113, 2006.

[14] C. C. Layman and M. W. Horner, "Comparing methods for measuring excess commuting and jobs-housing balance: empirical analysis of land use changes," Transportation Research Record, vol. 2174, no. 1, pp. 110-117, 2010.

[15] P. A. Waddell, "Accessibility and residential location: the interaction of workplace, housing tenure, residential mobiltity and location choice," in Proceedings of the Lincoln Land Institute TRED Conference, 1996.

[16] I. A. Inoa, N. Picard, and A. de Palma, "Commuting time and accessibility in a joint residential location, workplace, and job type choice model," in Proceedings of the Lausanne SustainCity Consortium Meeting, 2012.

[17] P. Waddell, "Exogenous workplace choice in residential location models: is the assumption valid?" Geographical Analysis, vol. 25, no. 1, pp. 65-82, 1993.

[18] M. A. I. Rivera and N. C. C. Tiglao, "Modeling residential location choice, workplace location choice and mode choice of two-worker households in Metro Manila," Eastern Asia Society for Transportation Studies, vol. 5, pp. 1167-1178, 2005.

[19] A. R. Pinjari, R. M. Pendyala, C. R. Bhat, and P. A. Waddell, "Modeling the choice continuum: an integrated model of residential location, auto ownership, bicycle ownership, and commute tour mode choice decisions," Transportation, vol. 38, no. 6, pp. 933-958, 2011.

[20] Á. Ibeas, R. Cordera, L. Dell'Olio, and P. Coppola, "Modelling the spatial interactions between workplace and residential location," Transportation Research A: Policy and Practice, vol. 49, pp. 110-122, 2013.

[21] J. E. Cho, D. Rodriguez, and Y. Song, "The role of employment subcenters in residential location decisions," Journal of Transport and Land Use, vol. 1, no. 2, pp. 121-151, 2008.

[22] T. L. Saaty, What Is the Analytic Hierarchy Process? Springer, Berlin, Germany, 1988.
[23] T. L. Saaty, "How to make a decision: the analytic hierarchy process," European Journal of Operational Research, vol. 48, no. 1, pp. 9-26, 1990.

[24] D. S. Faber and H. Korn, "Applicability of the coefficient of variation method for analyzing synaptic plasticity," Biophysical Journal, vol. 60, no. 5, pp. 1288-1294, 1991.

[25] H. S. Gau, C. Y. Hsieh, and C. W. Liu, "Application of grey correlation method to evaluate potential groundwater recharge sites," Stochastic Environmental Research and Risk Assessment, vol. 20, no. 6, pp. 407-421, 2006.

[26] Z.-H. Zou, Y. Yun, and J.-N. Sun, "Entropy method for determination of weight of evaluating indicators in fuzzy synthetic evaluation for water quality assessment," Journal of Environmental Sciences, vol. 18, no. 5, pp. 1020-1023, 2006. 


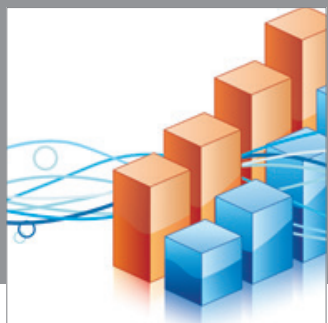

Advances in

Operations Research

mansans

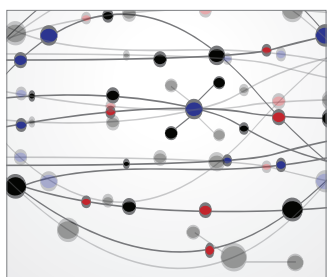

The Scientific World Journal
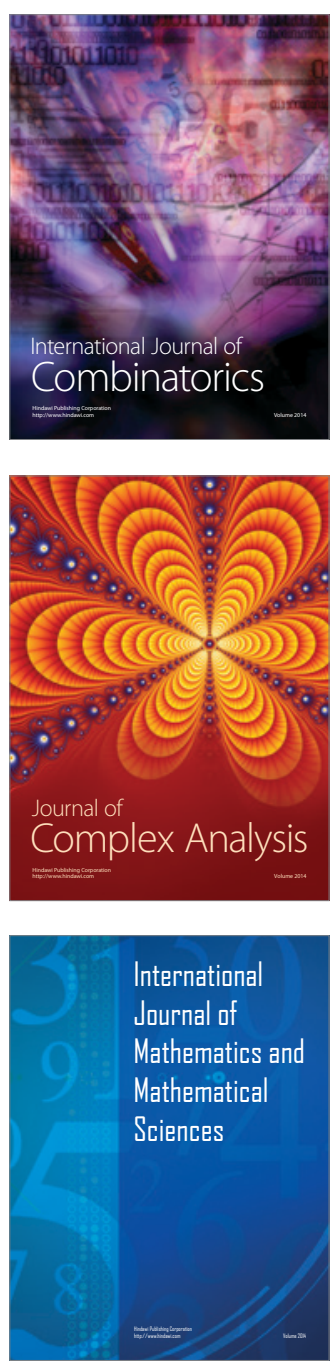
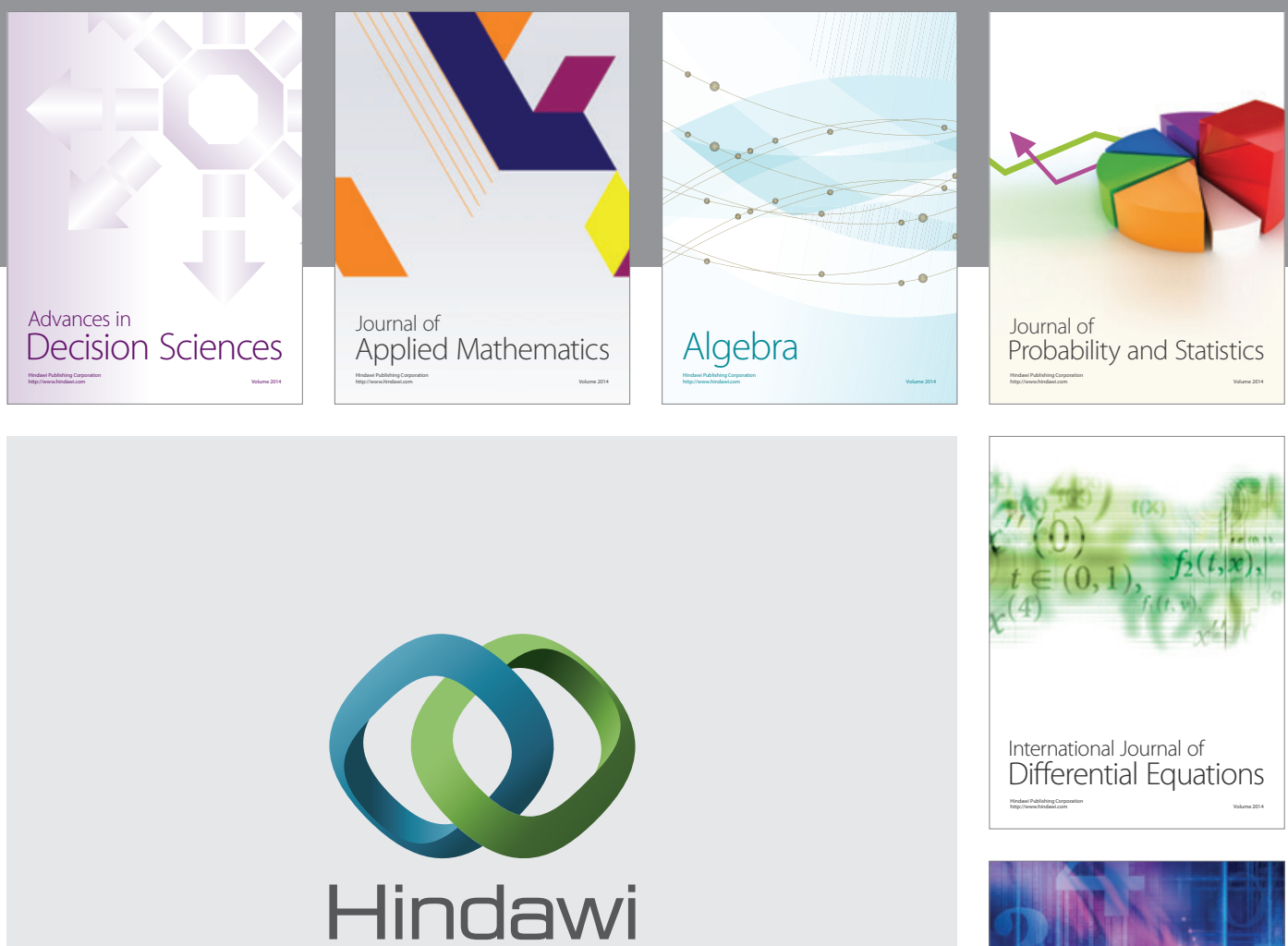

Submit your manuscripts at http://www.hindawi.com
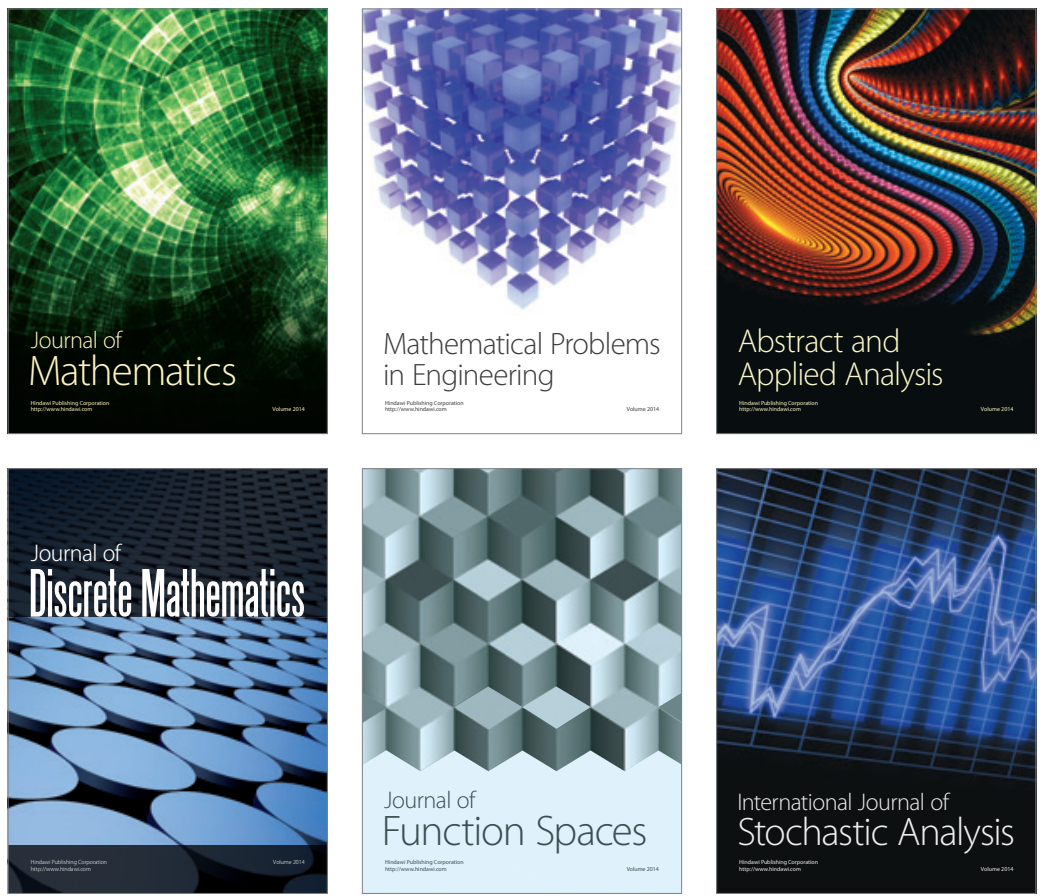

Journal of

Function Spaces

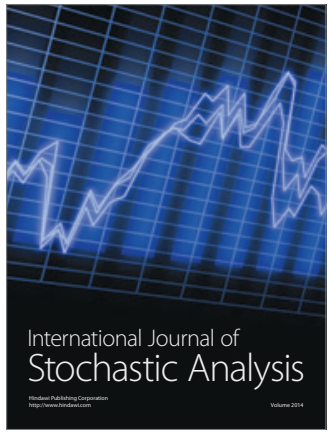

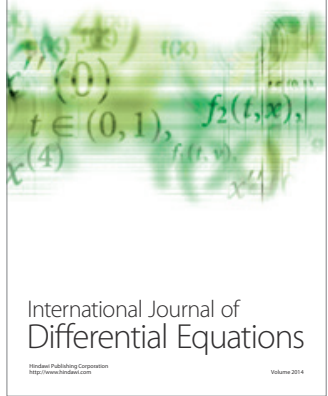
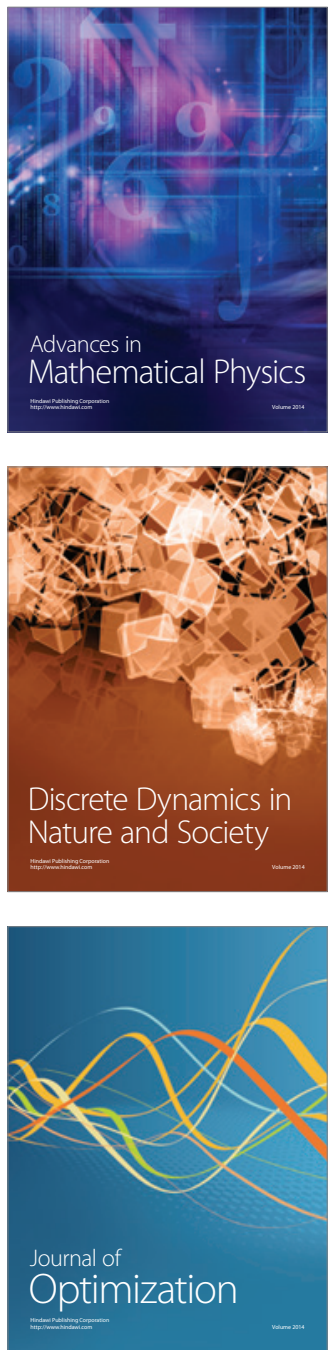